\title{
Perineal Ectopic Testis in an Adult
}

\author{
Gilbert Maranya, Bernard Mwero \\ Coast Province General Hospital, Mombasa, Kenya
}

Correspondence to: Dr Gilbert Maranya, P.O. Box 91066-80103 Mombasa, Kenya. Email: gilbertmaranya@gmail. com

\begin{abstract}
Testicular maldescent may be cryptorchid with descent being arrested along its normal pathway resulting in an abdominal, inguinal or high scrotal testis, or it may stray from the normal descent to settle in an ectopic site outside the scrotum; such as the perineum, pubic region, dorsum of the penis, femoral region, anterior abdominal wall and the contralateral scrotum. Management is orchidopexy through an inguinal crease incision as the length of the spermatic cord is normal. We report a 26 year old man with a
\end{abstract}

left perineal testis who underwent orchidopexy as the testicular volume was normal.

Key words: Ectopic testis, Perineal testis, Maldescended testis

Ann Afr Surg. 2017;14(1): 53-54. DOI:https://dx.doi.org/10.4314/aas.v14i1.11

(C) 2017 Annals of African Surgery. This work is licensed under the Creative Commons Attribution 4.0 International License.

\section{Introduction}

Maldescent of the testis is the most common anomaly of the genitalia (1). In most of these the descent is arrested along its normal pathway resulting in an abdominal, inguinal or high scrotal testis. Rarely a testis may stray from the normal descent to settle in an ectopic site outside the ipsilateral scrotum. Congenital fascial bands at the root of the scrotum could be the cause of migration of the testis to an ectopic site (2). Some locations of an ectopic testis are: the pubic region, dorsal penile area, femoral triangle, anterior abdominal wall, the opposite hemiscrotum and the perineum (2-8). Like undescended testes, ectopic testes are prone to trauma and testicular torsion. This is also associated with inguinal hernia and infertility $(2,5)$. Functional prognosis is similar $(9)$. Orchidopexy through an inguinal incision is the standard procedure as the cord structures are of normal length (2). If the testis is severely atrophic, orchidectomy is undertaken (10) and orchidopexy performed on the contralateral normal testis, which is the standard procedure for a solitary testis (11). We report a case of perineal ectopic testis in an adult at the Coast Province General Hospital, Mombasa, Kenya treated in May 2016.

\section{Case Presentation}

A 26 year old man presented at the surgical clinic of Coast Province General Hospital, Mombasa, Kenya, with a left sided perineal swelling that had been present since childhood. There was no discomfort. The patient was aware of having only one testis on the right. He had been investigated for infertility with a seminogram showing azoospermia. Examination of the patient revealed a normal right testis, empty left scrotum and a left perineal mass that elicited pain on pressure. The patient had an ultrasound scan of the scrotum and perineum that confirmed the left perineal mass as a testis. This testis, attached to the perineal skin, was of normal size and had a spermatic cord of adequate length. Left orchidopexy was done through an inguinal crease incision, with placement of the testis in a subdartos pouch. The operation details are depicted in Figure 1. 


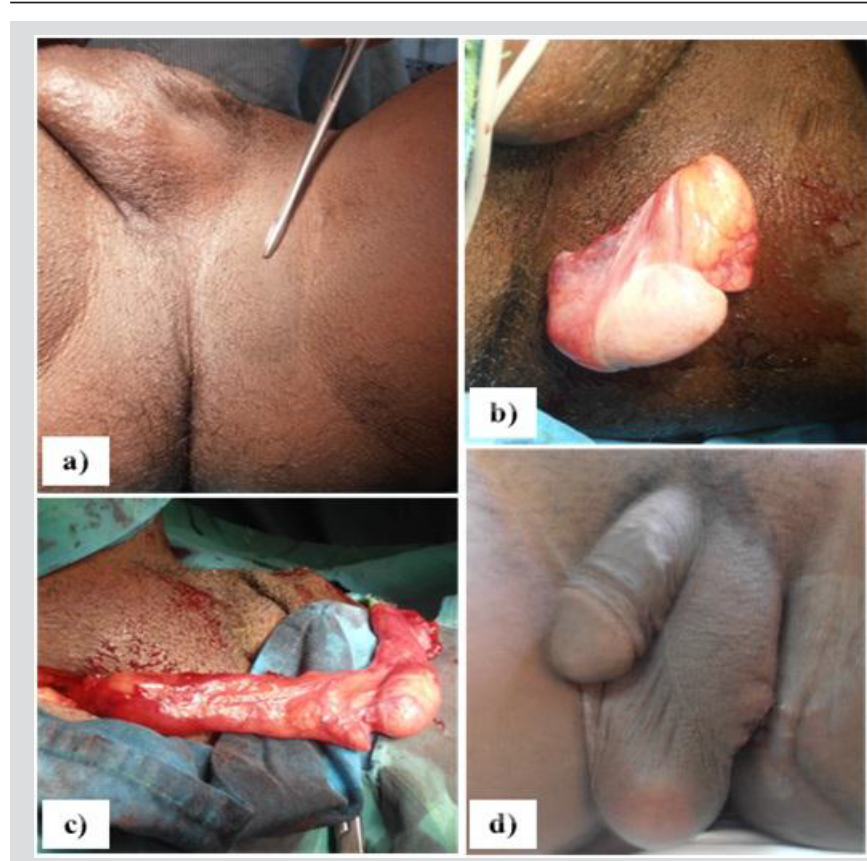

Figure 1: Left ectopic perineal testis. a) Forceps pointer on the testis. b) Perineal exposure of the testis. c) Testis brought out through an inguinal incision. d) Orchidopexy completed.

\section{Discussion}

The occurrence of ectopic testes is rare, with the perineal location as in our case being the most common (2). Most diagnoses of ectopic testes are made in early childhood $(2,7,9,10)$ with older children and adult presentation being rare $(3,4,12,13$,) as in our case. $\mathrm{Ku}(3)$ reported a perineal testis in a 36 year old, while Ates (12) reported the same in a 21 year old. In patients with an empty scrotum, clinical examination of the normal path of testicular descent and the areas of ectopic location, form the mainstay of diagnosis $(1,2,5)$ as was the situation in our patient with the ultrasound examination only confirming this. Our patient was managed by orchidopexy through an inguinal crease incision as the spermatic cord was of normal length as similarly stated in the literature $(2,10)$. The testicular volume was normal despite the tendency to atrophy with increased age (10). The contralateral testis was of normal volume; nevertheless the patient had infertility with azoospermia. This was a coincidental finding. An ectopic testis after puberty, may be normal in size but markedly deficient in spermatogenic components (3).

\section{Conclusion}

In maldescent of the testis with an empty scrotum, examination of the normal path of descent and probable sites of ectopic location is mandatory. Orchidopexy is straight forward with a good outcome.

\section{Acknowledgement}

We sincerely thank Dr Iqbal Khandwalla, Chief Administrator, Coast Province General Hospital Mombasa, Kenya for authority to publish this article and Jason Mwawana for the computer work.

\section{References}

1. Shah N, Barche A, Nirgiotis J. Unilateral Ectopic Testis: A Rare Congenital Genitourinary Anomaly. J Inv Med. 2015; 63: 401

2. Ramareddy RS, Alladi A, Siddappa OS. Ectopic Testis in Children: Experience with Seven Cases. J Ped Surg. 2013; 48: 538-41

3. Ku JH, Jeon JS, Lee NK, et al. Two Cases of Perineal Ectopic Testis. Int J Urol. 2000; 7: 307-9

4. Mota RL, Lopes FA, Rodrigues T, et al. Penile Testis Ectopia: A Rare Urogenital Condition. BMJ Case Rep. 2013; 10: 1136

5. Andrade K, Smith S, Goodarzian F. An Infant with an Ectopic Torsed Testis in the Abdominal Wall. Emerg Radiol. 2014; 21: 223-5

6. Pandey A, Rawat J, Pandey J, et al. Abdominal Wall Ectopic Testis Mimicking Spigelian Hernia. J Ped Surg. 2011; 46: 415-6

7. Soomro S, Mughal SA. Perineal Ectopic Testis - A Rare Encounter in Paediatric Surgical Practice. J Coll of Physic Surg Pakistan. 2008; 18: 386-7

8. Kuyumcuoglu U, Erol D, Matay E, et al. Bilateral Perineal Ectopic Testes. Int Urol Nephrol. 1990; 22: 271-3.

9. Nouira F, Ahmed YB, Jlidi S, et al. Management of Perineal Ectopic Testes. Tunisie Medicale. 2011; 89:47-9.

10. Celayir CA, Sok S, Sayman M, et al. Timing of Surgery in Perineal Ectopic Testes: Analysis of 16 Cases. Ped Surg Int. 2001; 17: 167-8.

11. Visser AJ, Heyns CF. Torsion of the Testis and its Appendages: Diagnosis and Management. Afr J Urol. 2004; 10: 85-91

12. Ateş F. Perineal Ectopic Testis. Turk Urol Dergisi. 2006; 32: 430-2.

13. Tasdemir C, Tuygun UO. Perineal Ectopic Testis: A Case Report. Eur Rev Med Pharm Sci. 2011; 15: 1318-9 